\title{
MODELLING THE INFLUENCE OF PORE SIZE ON THE RESPONSE OF \\ MATERIALS TO INFRARED LASERS - AN APPLICATION TO HUMAN ENAMEL
}

\author{
A. Vila Verde, Marta M. D. Ramos* \\ Department of Physics, University of Minho, Campus de Gualtar, 4710-057 BRAGA, \\ PORTUGAL
}

\begin{abstract}
We present an analytical model for a ceramic material (hydroxyapatite) containing nanometre-scale water pores, and use it to estimate the pressure at the pore as a function of temperature at the end of a single $0.35 \mu$ s laser pulse by Er:YAG $(2.94 \mu \mathrm{m})$ and $\mathrm{CO}_{2}(10.6 \mu \mathrm{m})$ lasers. Our results suggest that the pressure at the pore is directly related to pore temperature, and that very high pressures can be generated simply by the
\end{abstract}

\footnotetext{
* Corresponding Author: Tel. +351 253604 330; Fax. +351 253678 981; E-mail: marta@ fisica.uminho.pt Departamento de Física, Universidade do Minho, Campus de Gualtar, 4710-057 BRAGA, PORTUGAL
} 
thermal expansion of liquid water. Since the temperature reached at the pores at the end of the laser pulse is a strong function of pore size for Er:YAG lasers, but is independent of pore size for $\mathrm{CO}_{2}$ lasers, our present results provide a possible explanation for the fact that the enamel threshold ablation fluences are more variable for Er:YAG lasers than for $\mathrm{CO}_{2}$ lasers, and suggest that experimentalists should analyse their results accounting for factors (like age or type of tooth) that may change the pore size distribution in their samples.

PACS: 42.62._b; 42.62.Be; 44.30.pv; 02.70.Dh; 7.05.Tp

Keywords: Dental enamel; Laser ablation; Mesoscopic modelling of composites; Er:YAG laser; $\mathrm{CO}_{2}$ laser

Introduction

Laser ablation of composite materials is a procedure with increasing technological and biomedical importance; consequently, a lot of research has been devoted to understanding the mechanisms of ablation with the aim of developing a modelling capability that will guide the search for optimal laser operating parameters. The particular challenge in understanding the laser ablation mechanisms of composite materials is that the material's inhomogeneous chemical composition and microstructure must be explicitly included [1].

We have been developing general Finite Element models of mid-infrared laser ablation of composite materials with nanometre/micrometer scale pore-structure, and we 
have applied them to the specific problem of ablating human dental enamel using Er:YAG lasers at $2.9 \mu \mathrm{m}$ and $\mathrm{CO}_{2}$ lasers at $10.6 \mu \mathrm{m}$, a technique that may have significant impact in the treatment of dental caries. In our previous work [2], we presented finite element models of human dental enamel that explicitly included water pores, known to exist in this material. Using these models, we performed heat transfer simulations and we established that the maximum temperature reached in enamel waterpores at the end of a $0.35 \mu$ s laser pulse was significantly dependent of the pore size for the Er:YAG laser, but independent of pore size for the $\mathrm{CO}_{2}$ laser. Although at the time we did not perform simulations that would yield the stress distribution in the models, we postulated that the different pore temperatures would translate into differences in pore pressure. We concluded that, since the pore size distribution in enamel will vary greatly from sample to sample, the results of ablating enamel using Er:YAG lasers may be harder to predict and reproduce than when using $\mathrm{CO}_{2}$ lasers.

For the work presented here we build on the previously obtained pore temperatures, and use an analytical pore model to estimate the pore pressure as a function of pore temperature at the end of the laser pulse. The results presented in the present paper indicate that the temperature at the pore should be directly related to the pore pressure and thus support the hypotheses raised by our previous results [2].

\section{Model description}

In our previous work [2], we established the relationship between the maximum temperature reached in a water pore and the pore size, for a single $0.35 \mu$ s laser pulse by Er:YAG and $\mathrm{CO}_{2}$ lasers, and we suggested that the pore pressure would be directly 
related to the pore temperature. However, establishing a relationship between pore pressure and temperature is not straightforward, and it gets further complicated if the temperature is high enough to allow for water vaporization. In order to estimate the pore pressure at the end of a laser pulse, and to investigate whether water vaporization is likely to initiate or not before the onset of cracking, we developed and present now an analytical model of a single water pore in human dental enamel that builds on those previously obtained results.

This model consists of a spherical pore completely filled with water and surrounded by an infinite thickness of hydroxyapatite (HA), the main constituent of enamel. The stress-strain relationship between the specific volume (volume per unit mass), $\mathrm{V}$, of the pore and the pressure, $\mathrm{P}$, experienced at the pore is [3]

$$
\mathrm{V}=\mathrm{V}_{0}\left[1+\frac{1+v}{2 \mathrm{E}}\left(\mathrm{P}-\mathrm{P}_{0}\right)\right]^{3},
$$

where $V_{0}$ is the initial specific volume when the pressure at the pore is $P_{0}, v$ is Poisson's ratio and $\mathrm{E}$ is Young's modulus for HA. In the particular system being studied, $\mathrm{P}_{0}$ is the atmospheric pressure $\left(1 \times 10^{5} \mathrm{~Pa}\right), \mathrm{V}_{0}\left(0.00100888 \mathrm{~m}^{3} / \mathrm{kg}\right)$ is the specific volume of water at pressure $\mathrm{P}_{0}$ and temperature $37^{\circ} \mathrm{C}$ and the material parameters for $\mathrm{HA}$ are $\mathrm{v}=0.28$ [4] and $\mathrm{E}=1.13 \times 10^{11} \mathrm{~Pa}$ [5]. Majaron [3] demonstrated that the onset of ablation should occur when the pore pressure exceeds HA's ultimate tensile strength (UTS), if we assume that the onset of ablation corresponds to the onset of cracking and that cracking will take place whenever any component of the stress tensor in HA exceeds this material's UTS.

On the other hand, the specific volume of water in the pore is a function of water temperature and pressure; this relationship can be expressed by an equation of state (EOS) for bulk water, since work done by Giaya, Liu, Borggreven and co-workers [6-8] strongly 
suggests that water in HA pores as small as $30 \times 30 \times 30 \mathrm{~nm}^{3}$ [9] because of its accuracy and simplicity:

$$
\mathrm{V}=\mathrm{V}_{0 \mathrm{~T}}\left[1-\mathrm{A}_{\mathrm{T}} \ln \left(1+\frac{\mathrm{P}}{\mathrm{B}_{\mathrm{T}}}\right)\right]
$$

where

$$
\begin{gathered}
\mathrm{V}_{0 \mathrm{~T}}=\mathrm{V}_{\mathrm{P} 0 \mathrm{~T} 0}\left(1+\xi_{1} \mathrm{~T}+\xi_{2} \mathrm{~T}^{2}+\xi_{3} \mathrm{~T}^{3}+\xi_{4} \mathrm{~T}^{4}+\xi_{5} \mathrm{~T}^{5}\right), \\
\mathrm{A}_{\mathrm{T}}=\mathrm{A}_{0}\left(1+\eta_{1} \mathrm{~T}+\eta_{2} \mathrm{~T}^{2}+\eta_{3} \mathrm{~T}^{3}\right)
\end{gathered}
$$

and

$$
\mathrm{B}_{\mathrm{T}}=\mathrm{B}_{0}\left(1+\varsigma_{1} \mathrm{~T}+\varsigma_{2} \mathrm{~T}^{2}+\varsigma_{3} \mathrm{~T}^{3}\right) .
$$

Lyons obtained the values of the constants $\mathrm{V}_{\text {Рото }}, \mathrm{A}_{0}, \mathrm{~B}_{0}, \xi_{\mathrm{i}}, \eta_{\mathrm{i}}$ and $\zeta_{\mathrm{i}}$ used in eqs. $2,3,4$ and 5 by fitting these equations to experimental measurements of temperature, pressure and mass volume for liquid water; the values used in this work can be found in Table 1 . The same author established the validity of eq. 2 for temperatures in the range of 0 to 100 ${ }^{\circ} \mathrm{C}$ and pressures between 0.1 and $100 \mathrm{MPa}$; however, we compared the results of eq. 2 with experimental data in references [10,11], and have found that it holds well for temperatures up to $200{ }^{\circ} \mathrm{C}$ and pressures up to $500 \mathrm{MPa}$.

Using eqs. 1 and 2, we obtained the expression that relates the pressure at the pore with the pore temperature; we should highlight that the pressure at the pore is not a function of pore size, but of the temperature at the pore and the mechanical properties of the elastic medium surrounding the pore.

$$
\mathrm{V}_{0 \mathrm{~T}}\left[1-\mathrm{A}_{\mathrm{T}} \ln \left(1+\frac{\mathrm{P}}{\mathrm{B}_{\mathrm{T}}}\right)\right]=\mathrm{V}_{0}\left(1+\frac{1+v}{2 \mathrm{E}}\left(\mathrm{P}-\mathrm{P}_{0}\right)\right)^{3}
$$


Analytically solving this new equation with respect to the pressure to obtain a general solution is not practical, so instead we used Maple 8.0 to solve it numerically using the material parameters for $\mathrm{HA}$ and the pore temperatures obtained in our previously published work [2], which can be found in Table 2. Because the local mechanical properties (E and $v$ ) of HA may differ significantly from the available average values, we investigated the influence of $\mathrm{E}$ and $v$ on the results by independently varying both those parameters by $\pm 20 \%$, and by varying $\mathrm{E}$ by \pm 1 and \pm 2 orders of magnitude. The consequences of varying Poisson's ratio more than $\pm 20 \%$ were not investigated since for most materials $v$ can only take values between 0 and 0.5 and it is not likely that $v$ for HA will be close to those extreme values.

Results and discussion

Equation 6 has non-trivial solutions in the temperature range we are interested; the results obtained using this equation for the pressure reached in the different-sized water pores are shown in Table 2. These results strongly suggest that there is a clear dependence between the pore pressure and pore temperature; surprisingly, they also indicate that very high pressures may be reached in the absence of water vaporization, caused solely by the thermal expansion of liquid water. Indeed, the pressures reached in our models are higher than the UTS for polished, fully dense HA $\left(1.15 \times 10^{8} \mathrm{~Pa},[12]\right)$, which suggests that cracking may start when the temperature at the water pores is as low as $120^{\circ} \mathrm{C}$. Because the pressure experienced at the water pores is high enough to prevent water vaporization from taking place, the results also suggest that water vaporization may 
begin only after cracking of the pore walls has occurred, a hypothesis that so far has not been considered by other authors.

In order to assess the influence of the chosen values of $E$ and $v$ on our results, and thus evaluate the level of confidence we can have in them, we solved equation 6 for the temperatures indicated in Table 2 and varying $\mathrm{E}$ and $v$ independently by $\pm 20 \%$. The values of pressure varied by $2 \%$ or less, which indicates that our results are not particularly sensitive to small variations in $E$ and $v$. We then varied $E$ by \pm 1 order of magnitude, and we found that while using $\mathrm{E}=1 \times 10^{12} \mathrm{~Pa}$ only caused a $5 \%$ increase in pore pressure, using $\mathrm{E}=1 \times 10^{10} \mathrm{~Pa}$ caused a very significant $33 \%$ decrease in pore pressure. Using $\mathrm{E}=1 \times 10^{13} \mathrm{~Pa}$ caused a mere $6 \%$ increase in pore pressure, but using $\mathrm{E}$ $=1 \times 10^{9}(2$ orders of magnitude lower $)$ caused a $81 \%$ decrease in pore pressure. This dependence of pore pressure on the value of $\mathrm{E}$ and the fact that the local mechanical properties of hydroxyapatite may vary significantly from the average values (of both E and UTS) that are available in the literature indicate that the present results should be interpreted cautiously from a quantitative point of view. Nevertheless, our results strongly suggest that the thermal expansion of liquid pore water may play a significant role in cracking and ablation of human dental enamel.

\section{Conclusions}

Our present results indicate that the pressure at enamel water pores is directly related to the pore temperature, and that very high pressures can be reached in the absence of water vaporization, caused solely by the thermal expansion of liquid porewater. Since our previous work [2] suggests that the pore temperature reached at the end 
of a single $0.35 \mu$ s laser pulse is a strong function of pore size for Er:YAG lasers, but is independent of pore size for $\mathrm{CO}_{2}$ lasers, we propose that the experimentally observed higher variability in the threshold enamel ablation fluences by Er:YAG lasers relative to $\mathrm{CO}_{2}$ lasers is a consequence of the variability in pore size that can be expected in a biological material like enamel. Consequently, our results indicate that researchers conducting ablation of any porous composite material such as enamel should take in consideration factors that may affect the pore size distribution in the material, in particular if the laser wavelength is absorbed differently by the different components of the material.

\section{REFERENCES}

[1] A.M. Stoneham and J.H. Harding, Nat. Mater., 2 (2003) 77.

[2] A. Vila Verde, M.M.D. Ramos, A.M. Stoneham and R.M. Ribeiro, 238 (2004) 410.

[3] B. Majaron, P. Plestenjak and M. Lukac, Appl. Phys. B, 69 (1999) 71.

[4] D.E. Grenoble, J.L. Katz, K.L. Dunn, R.S. Gilmore and K.L. Murty, J. Biomed. Mater. Res., 6 (1972) 221, in 'Dental Tables' at http://www.lib.umich.edu/.

[5] M. Braden, in Y. Kawamura (Ed), Physiology of Oral Tissues, Frontiers of Oral Physiology, Vol 2, S. Karger AG, Basel, 1976, p. 1.

[6] A. Giaya and R.W. Thompson, J. Chem. Phys., 117 (2002) 3464. 
[7] Y.-C. Liu, Q. Wang and L.-H. Lu, 381 (2003) 210.

[8] J.M.P.M. Borggreven, F.C.M. Driessens and J.W.E. Vandijk, 25 (1980) 345.

[9] C.G. Lyons, J. Mol. Liq., 69 (1996) 269.

[10] J.R. Cooper and E.J. Le Fevre, Thermophysical properties of water substance Student's tables in SI units, Edward Arnold Ltd, London, 1975.

[11] S. Wiryana, L.J. Slutsky and J.M. Brown, Earth Planet. Sci. Lett., 163 (1998) 123.

[12] J. Czernuszka, in D. Bloor, M.C. Flemings, R. Brook, S. Mahajan and R. Cahn (Eds), The encyclopedia of advanced materials, Vol 4, Elsevier Science Ltd, Cambridge, Great Britain, 1994, p. 1076. 
Table 1 - Parameters used for the Equation of State for water.

\begin{tabular}{|l|l|}
\hline $\mathrm{B}_{0}\left(\mathrm{~N} / \mathrm{m}^{2}\right)$ & $2.71 \mathrm{E}+08$ \\
\hline $\mathrm{A}_{0}$ & $1.38 \mathrm{E}-01$ \\
\hline $\mathrm{V}_{\mathrm{p} 0 \mathrm{t} 0}\left(\mathrm{~m}^{3} / \mathrm{kg}\right)$ & $1.00021195720 \mathrm{E}-03$ \\
\hline$\xi_{1}\left({ }^{\circ} \mathrm{C}^{-1}\right)$ & $-6.10804506610 \mathrm{E}-05$ \\
\hline$\xi_{2}\left({ }^{\circ} \mathrm{C}^{-2}\right)$ & $8.26422147620 \mathrm{E}-06$ \\
\hline$\xi_{3}\left({ }^{\circ} \mathrm{C}^{-3}\right)$ & $-6.25191522510 \mathrm{E}-08$ \\
\hline$\xi_{4}\left({ }^{\circ} \mathrm{C}^{-4}\right)$ & $3.96577772140 \mathrm{E}-10$ \\
\hline$\xi_{5}\left({ }^{\circ} \mathrm{C}^{-5}\right)$ & $-1.03766115850 \mathrm{E}-12$ \\
\hline$\eta_{1}\left({ }^{\circ} \mathrm{C}^{-1}\right)$ & $1.83447912390 \mathrm{E}-03$ \\
\hline$\eta_{2}\left({ }^{\circ} \mathrm{C}^{-2}\right)$ & $-3.94832209280 \mathrm{E}-05$ \\
\hline$\eta_{3}\left({ }^{\circ} \mathrm{C}^{-3}\right)$ & $1.32756265960 \mathrm{E}-07$ \\
\hline$\zeta_{1}\left({ }^{\circ} \mathrm{C}^{-1}\right)$ & $9.43239862720 \mathrm{E}-03$ \\
\hline$\zeta_{2}\left({ }^{\circ} \mathrm{C}^{-2}\right)$ & $-1.43696702930 \mathrm{E}-04$ \\
\hline$\zeta_{3}\left({ }^{\circ} \mathrm{C}^{-3}\right)$ & $4.56081249050 \mathrm{E}-07$ \\
\hline
\end{tabular}

Table 2: Maximum temperature and pressure at the pores for all the models (at the end of the laser pulse).

\begin{tabular}{|c|c|c|c|c|}
\cline { 2 - 3 } \multicolumn{1}{c|}{} & \multicolumn{2}{c|}{ Er:YAG } & \multicolumn{2}{c|}{$\mathrm{CO}_{2}$} \\
\hline $\begin{array}{c}\text { Pore dimensions } \\
\left(\mathrm{nm}^{3}\right)\end{array}$ & $\begin{array}{c}\text { Temperature } \\
\left({ }^{\circ} \mathrm{C}\right)\end{array}$ & $\begin{array}{c}\text { Pressure } \\
(\mathrm{Pa})\end{array}$ & $\begin{array}{c}\text { Temperature } \\
\left({ }^{\circ} \mathrm{C}\right)\end{array}$ & $\begin{array}{c}\text { Pressure } \\
(\mathrm{Pa})\end{array}$ \\
\hline $30 \times 30 \times 30$ & 118 & $1.1 \times 10^{8}$ & & \\
\hline $50 \times 50 \times 50$ & 124 & $1.1 \times 10^{8}$ & & \multirow{2}{*}{$1.8 \times 10^{8}$} \\
\hline $70 \times 70 \times 70$ & 134 & $1.3 \times 10^{8}$ & & \\
\hline $90 \times 90 \times 90$ & 147 & $1.6 \times 10^{8}$ & & \\
\hline $110 \times 110 \times 110$ & 162 & $1.9 \times 10^{8}$ & & \\
\hline $130 \times 130 \times 130$ & 176 & $2.2 \times 10^{8}$ & & \\
\hline
\end{tabular}

